\title{
Crystallization of Palladium(II)-Pyridylazophenol Complex at the Liquid-Liquid Interface
}

\author{
Akira OHASHI* and Takafusa KIMINARITA \\ Graduate School of Science and Engineering, Ibaraki University, 2-1-1 Bunkyo, Mito, Ibaraki 310-8512, \\ Japan
}

(Received May 22, 2020; Accepted January 5, 2021)

The crystallization of the palladium(II) complex with 2-(5-bromo-2-pyridylazo)-5-diethylaminophenol (HL) at the liquid-liquid interface was investigated in the heptane-toluene mixture/water system. Interfacial crystallization of PdLCl did not occur in the heptane/water system, whereas it occurred in the heptane-toluene mixture/water system. The crystal size distribution of $\mathrm{PdLCl}$ formed at the liquid-liquid interface strongly depended on the PdLCl solubility in the organic phase and the formation rate. Larger PdLCl crystals formed at the liquid-liquid interface under the higher toluene ratio, higher $\mathrm{Pd}(\mathrm{II})$ concentration and lower $\mathrm{pH}$ conditions.

\section{Introduction}

The liquid-liquid interface has received a great deal of attention as a new reaction field for synthesis of organic and inorganic compounds [1,2], because the liquid-liquid interface has specific characteristics, such as a nanometer sized thickness, a drastic change in solvent environment and a two-dimensional region. The formation of crystals, aggregates and precipitates at the liquid-liquid interface in solvent extraction system appeared very often. There have been several reports about the formation of the crystals at the liquidliquid interface [3-6]. Previously, we reported some aggregate formations at the liquid-liquid interface [7,8]. These results suggested the possibility of the liquid-liquid interface as the specific synthesis field that differs from the bulk phase. The accumulation of basic research on the formation of crystals and aggregates at the liquid-liquid interface is effective in clarifying the properties of the liquid-liquid interface as a reaction field.

2-(5-Bromo-2-pyridylazo)-5-diethylaminophenol (5-Br-PADAP or HL) is a sensitive reagent in the determination of trace metal ions and forms stable and colored complexes with various metal ions as a trident ligand $[9,10]$. Previously, we reported that 5-Br-PADAP extracted Pd(II) ion from hydrochloric acid into toluene as $\mathrm{PdLCl}$ [11]. However, $\mathrm{PdLCl}$ was rarely extracted into heptane and $\mathrm{PdLCl}$ aggregates were formed at the heptane/water interface [7].

In this paper, we report the interfacial crystallization of $\mathrm{PdLCl}$ in the heptane-toluene mixture/water system. Factors affecting crystal growth at the liquid-liquid interface are investigated. We clarify the usefulness of crystallization at the liquid-liquid interface. 


\section{Experimental}

\subsection{Reagents}

5-Br-PADAP (HL) was purchased from Tokyo Chemical Industry Co., Ltd. and used as received. Heptane and toluene (HPLC grade, Kanto Chemical Co., Inc.) were used as received. A stock solution of palladium(II) was prepared by dissolving palladium(II) chloride (GR, Kanto Chemical Co., Inc.) in $0.1 \mathrm{M}$ hydrochloric acid (GR, FUJIFILM Wako Pure Chemical Co.). Sodium chloride (GR) was purchased from FUJIFILM Wako Pure Chemical Co. Water was distilled and deionized with a Milli-Q system (Milli-Q SP.TOC., Millipore).

\subsection{Liquid-liquid extraction}

The batch method was carried out to investigate the extraction behavior of Pd(II) with HL. Equal volumes $(5 \mathrm{ml})$ of $1.0 \times 10^{-3} \mathrm{M} \mathrm{Pd}(\mathrm{II})$ aqueous solution and $2.0 \times 10^{-5} \mathrm{M} \mathrm{HL}$ organic solution (Toluene, heptane, or their mixture) were shaken in a glass tube for $8 \mathrm{~h}$ in a thermostated room at $298 \mathrm{~K}$. After the centrifugal separation, the absorption spectra of the organic phase were measured with a spectrophotometer (V-560, JASCO) to determine the extractability of $\mathrm{PdLCl}$ into the organic phase. The $\mathrm{pH}$ and ionic strength were fixed at 1.0 and $0.1 \mathrm{M}$ with $\mathrm{HCl}$, respectively.

\subsection{Observation of microscopic images}

A Pd(II) aqueous solution (1.5 mL) was introduced in a covered petri dish, and then $1.0 \times 10^{-4} \mathrm{M} \mathrm{HL}$ organic solution $(1.0 \mathrm{~mL})$ was carefully added onto the aqueous phase. The microscopic images of the PdLCl crystals formed at the liquid-liquid interface were obtained directly above the organic phase at 60 -fold magnification by a digital microscope (Intel Play QX3 Computer Microscope) connecting to a computer at predetermined time intervals. The inner diameter and inner height of the petri dish were $27 \mathrm{~mm}$ and $12 \mathrm{~mm}$, respectively. Heptane and its mixtures with toluene were used as an organic solvent. Size distribution of interfacial PdLCl crystal at equilibrium was observed in the following way. The crystals formed at the liquidliquid interface were pipetted and transferred on a glass slide. The 150 crystals on a glass slide were randomly selected and imaged at 200-fold magnification by a digital microscope. The size distribution of the 150 crystals was obtained from their images. The Pd(II) concentration was changed from $5.0 \times 10^{-4}$ to $5.0 \times 10^{-3}$ $\mathrm{M}$. The $\mathrm{pH}$ value was varied from 1.0 to 3.0 with $\mathrm{HCl}$ and $\mathrm{NaCl}$. The ionic strength was fixed at $0.1 \mathrm{M}$.

A PdLCl crystal produced from the bulk was prepared in the following way. A saturated toluene solution of PdLCl was placed in a petri dish, and toluene was volatilized over 2 days at room temperature. This operation was repeated $2-3$ times to grow the crystals larger. Dark-purple and prismatic crystals were obtained. Crystal structure analysis was performed by the same method previously reported [12].

\section{Results and Discussion}

\subsection{Extractability of PdLCl into the heptane-toluene mixed phase}

Previously, we reported that $\mathrm{PdLCl}$ was completely extracted into the toluene phase but hardly into the heptane phase [7,11]. The extraction behavior of $\mathrm{Pd}(\mathrm{II})$ with $\mathrm{HL}$ into the heptane-toluene mixed phase was investigated by the batch method. Figure 1 shows the effect of toluene percentage on the PdLCl concentration in the heptane-toluene mixed solution at equilibrium. The PdLCl concentration in the organic phase was estimated from the absorbance at $564 \mathrm{~nm}$ using molar absorptivity $\left(\varepsilon_{564}=4.33 \times 10^{4} \mathrm{M}^{-1} \mathrm{~cm}^{-1}\right.$ [11]) of $\mathrm{PdLCl}$ in toluene. It was assumed that the molar absorptivity of $\mathrm{PdLCl}$ in the organic phase did not 


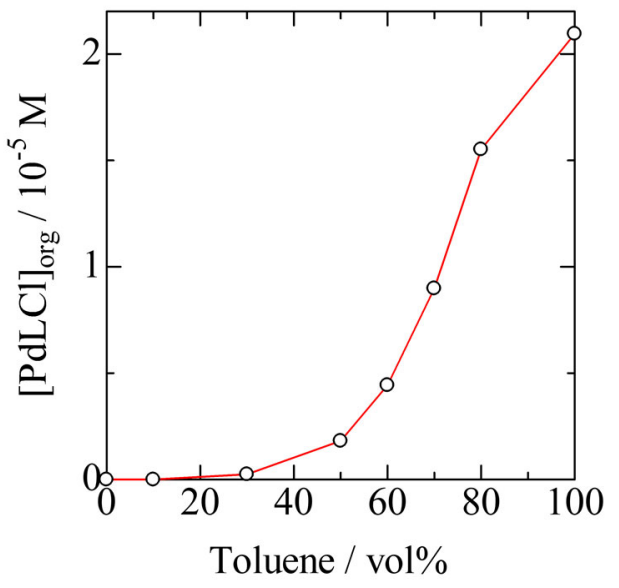

Figure 1. Effect of toluene percentage on the equilibrium concentration of $\mathrm{PdLCl}$ in the heptane-toluene mixed phase. $[\mathrm{Pd}(\mathrm{II})]=1.0 \times 10^{-3}$ $\mathrm{M},[\mathrm{HL}]=2.0 \times 10^{-5} \mathrm{M}, \mathrm{pH} 1.0$.

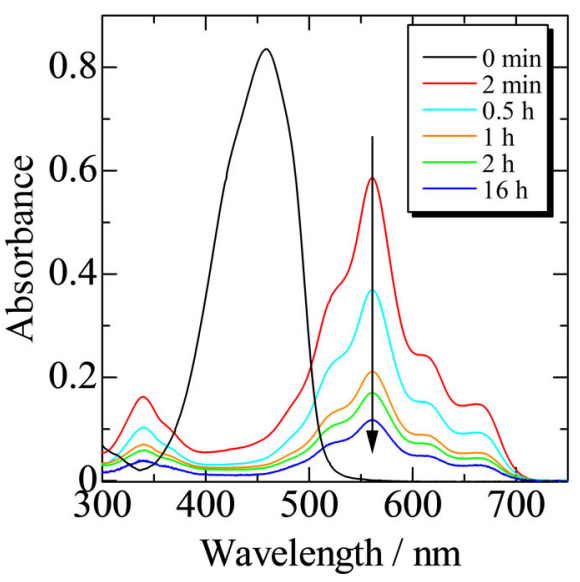

Figure 2. Absorption spectral change of the organic phase in the $50 \%$ heptane- $50 \%$ toluene system. $[\mathrm{Pd}(\mathrm{II})]=1.0 \times 10^{-3} \mathrm{M},[\mathrm{HL}]=2.0 \times 10^{-5}$ $\mathrm{M}, \mathrm{pH} 1.0$.

change even if the ratio of toluene and heptane changed. At equilibrium, absorption for HL in the organic phase was not observed at all in all systems, indicating that all HL reacted with $\mathrm{Pd}(\mathrm{II})$. In the $100 \%$ toluene system, formed PdLCl was completely extracted into the organic phase at equilibrium. However, the equilibrium concentration of $\mathrm{PdLCl}$ in the organic phase decreased with a decrease in toluene percentage. Purple solids were observed at the liquid-liquid interface in the low toluene ratio systems. Figure 2 shows absorption spectral change of the organic phase in the $50 \%$ heptane- $50 \%$ toluene system. After 2 minutes of shaking, the absorption spectrum of HL was not observed due to the rapid complexation and only that of PdLCl was observed. A relatively high concentration of PdLCl was observed in the organic phase immediately after the start of the reaction. However, the concentration of PdLCl in the organic phase decreased over time. At equilibrium, $\mathrm{PdLCl}$ was hardly observed in the organic phase, and purple solids were observed at the liquid-liquid interface. These results suggest that PdLCl was once extracted into the heptanetoluene mixed phase and then precipitated at the liquid-liquid interface.

\subsection{Crystals of PdLCl formed at the liquid-liquid interface}

\subsubsection{Effect of ratio of heptane and toluene}

An organic solution containing HL was carefully added onto the Pd(II) aqueous solution in a covered petri dish. The solid species formed at the liquid-liquid interface were observed by a digital microscope. Figures 3(a)-3(e) show microscopic images of PdLCl solid species at the liquid-liquid interface in systems with various heptane and toluene ratios at equilibrium. Figure 3(f) shows an image of a PdLCl crystal produced from the bulk of a PdLCl toluene solution. It was confirmed that the structure of this crystal was the same as that previously produced from an PdLCl acetone solution [12]. In the $100 \%$ heptane system, a film-like solid species was observed at the interface. However, crystalline solid species at the interface increased as the proportion of toluene increased. The shape of the crystalline solid species produced at the interface was like that of the crystal produced from the bulk. This similarity suggests that the structure of the interfacial crystalline solid species is the same as that of the crystals formed from the bulk, though the 
(a) $100 \%$ heptane

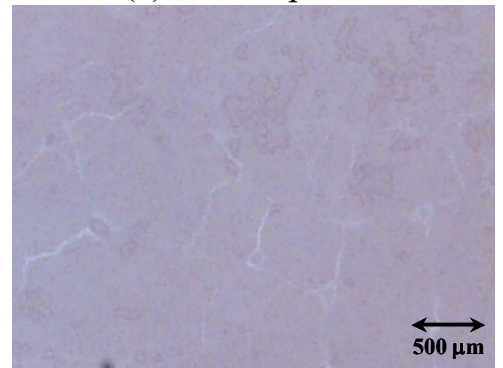

(d) $50 \%$ heptane $+50 \%$ toluene

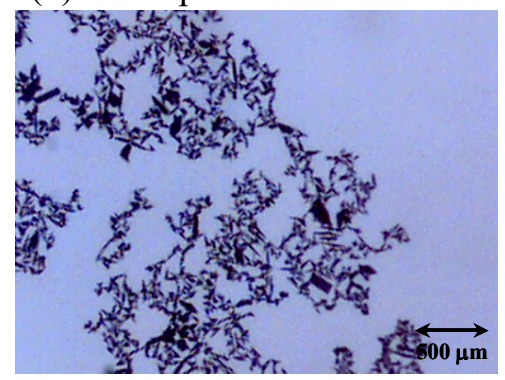

(b) $80 \%$ heptane $+20 \%$ toluene

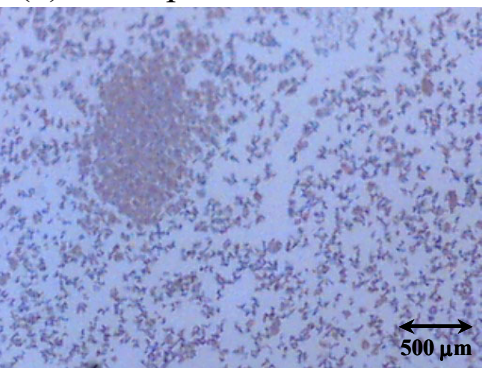

(e) $40 \%$ heptane $+60 \%$ toluene

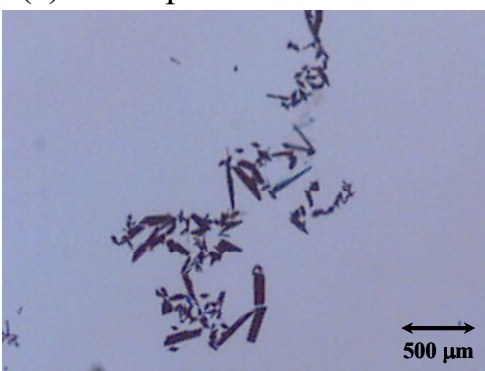

(c) $60 \%$ heptane $+40 \%$ toluene

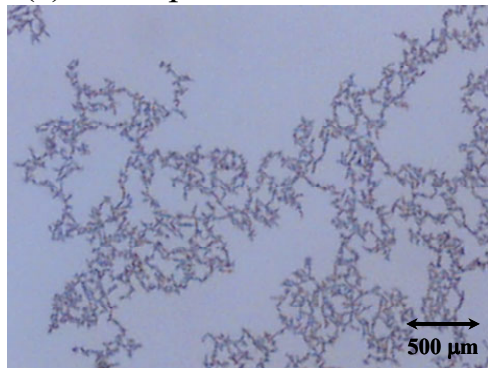

(f)crystal prepared from bulk

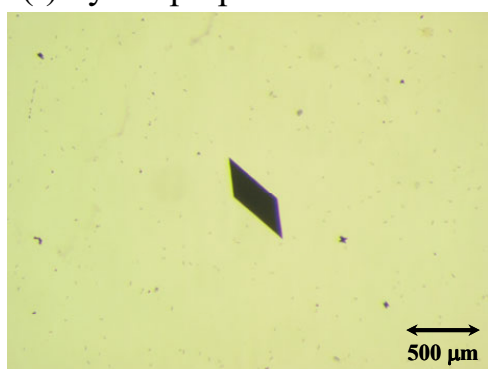

Figure 3. Microscopic images of PdLCl solid species at the liquid-liquid interface in systems with various heptane and toluene ratios and a $\mathrm{PdLCl}$ crystal prepared from the bulk.

structure of the crystalline solid species formed at the interface has not yet been confirmed. PdLCl was notextracted into heptane but was extracted once into the heptane-toluene mixed phase. It was found that the extraction of $\mathrm{PdLCl}$ into the organic phase is important for the crystallization at the liquid-liquid interface. The effect of the ratio of heptane and toluene on the size of crystals formed at the interface was investigated. Figure 4 shows the size distributions of the interfacial PdLCl crystals at various ratios of heptane and toluene. The crystal size increased as the toluene ratio increased. The averages of crystals were $81 \mu^{2}$ in the $60 \%$ heptane- $40 \%$ toluene system, $3.6 \times 10^{2} \mu \mathrm{m}^{2}$ in the $50 \%$ heptane- $50 \%$ toluene system, and $9.8 \times 10^{2} \mu \mathrm{m}^{2}$ in the $40 \%$ heptane- $60 \%$ toluene system. It is well known that crystal size distribution mainly depends on the crystallization kinetics [13]. This kinetics is controlled by supersaturation. We reported that the formation rate of PdLCl was faster in the toluene/water system than in the heptane/water system [7,11]. Therefore, the formation rate of $\mathrm{PdLCl}$ is slower in higher toluene ratio system. Moreover, the solubility of $\mathrm{PdLCl}$ in the organic phase is higher in the higher toluene ratio system. These cause the slower crystal formation rate at the interface by lower supersaturation in the higher toluene ration system. These results are thought to produce the formation of larger interfacial crystals in higher toluene ratio systems.

\subsubsection{Effect of Pd(II) concentration}

The effect of the Pd(II) concentration on the size of crystals formed at the interface was investigated in the $50 \%$ heptane- $50 \%$ toluene system. The $\mathrm{pH}$ value was fixed at 1.0 . At equilibrium, it was confirmed that all $\mathrm{HL}$ reacted with $\mathrm{Pd}(\mathrm{II})$ in all systems. The averages of the interfacial crystals at $[\mathrm{Pd}(\mathrm{II})]=5.0 \times 10^{-4}$ $\mathrm{M}, 1.0 \times 10^{-3} \mathrm{M}$, and $5.0 \times 10^{-3} \mathrm{M}$ were $9.0 \times 10^{2} \mu \mathrm{m}^{2}, 3.6 \times 10^{2} \mu \mathrm{m}^{2}$, and $1.2 \times 10^{2} \mu \mathrm{m}^{2}$, respectively. The lower the Pd (II) concentration, the larger the crystals formed at the interface. The formation rate of PdLCl become slower as the $\mathrm{Pd}$ (II) concentration is lower, causing the lower supersaturation in the lower $\mathrm{Pd}$ (II) 
concentration system. Therefore, it is thought that the formation of larger interfacial crystals in the lower $\mathrm{Pd}(\mathrm{II})$ concentration system.

(a)

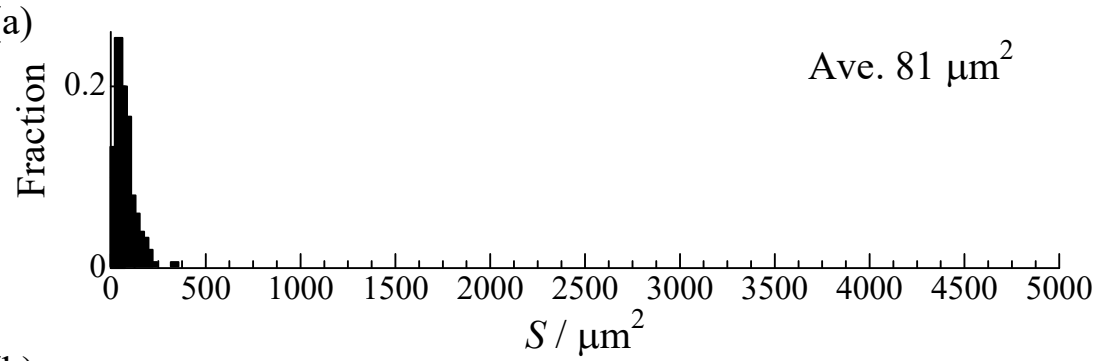

(b)

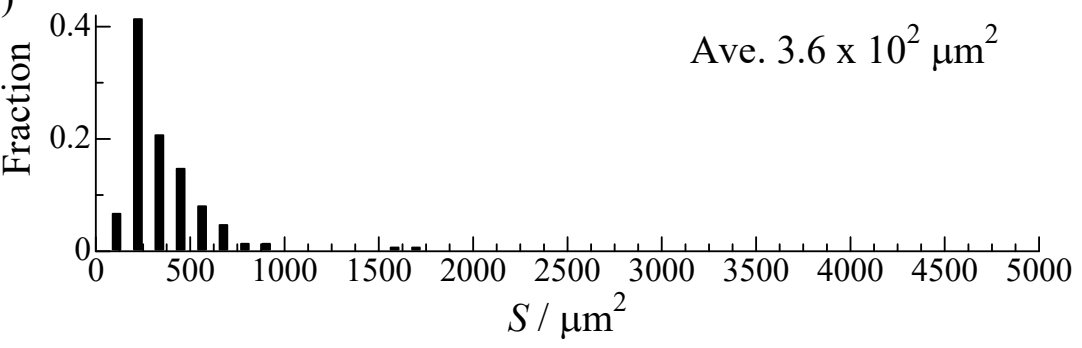

(c)

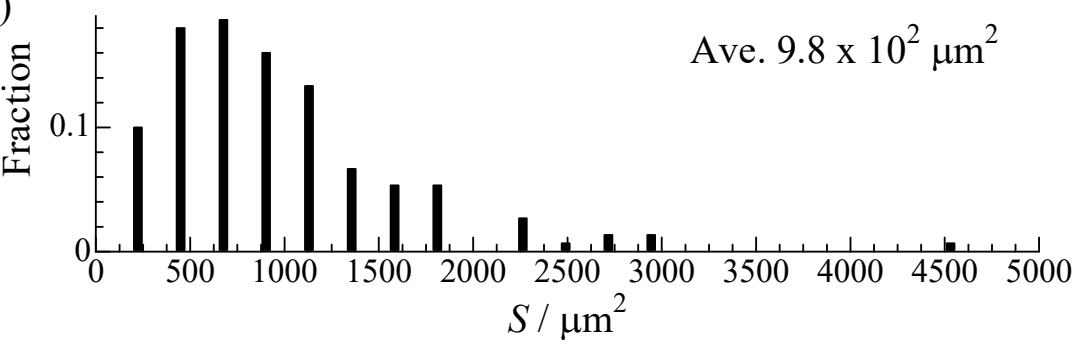

Figure 4. Size distribution of PdLCl crystals formed at the liquid-liquid interface. (a) $60 \%$ heptane + $40 \%$ toluene, (b) $50 \%$ heptane $+50 \%$ toluene, (c) $40 \%$ heptane $+60 \%$ toluene; $[\mathrm{Pd}(\mathrm{II})]=1.0 \times 10^{-3}$ $\mathrm{M},[\mathrm{HL}]=1.0 \times 10^{-4} \mathrm{M}, \mathrm{pH} 1.0$.

\subsubsection{Effect of $\mathrm{pH}$}

The effect of $\mathrm{pH}$ on the size of crystals formed at the interface was investigated in the $50 \%$ heptane$50 \%$ toluene system. The $\mathrm{Pd}(\mathrm{II})$ concentration was fixed at $1.0 \times 10^{-3} \mathrm{M}$. At equilibrium, it was confirmed that all HL reacted with Pd(II) in all systems. Figure 5 shows the dependency of PdLCl crystal growth on time at the liquid-liquid interface. The rate of the crystal growth at $\mathrm{pH} 3.0$ was slower than that at $\mathrm{pH} 1.0$, and the larger crystals were formed at $\mathrm{pH} 3.0$ than $\mathrm{pH} 1.0$. The averages of the interfacial crystals at $\mathrm{pH}=$ 1.0, 2.0 and 3.0 were $3.6 \times 10^{2} \mu \mathrm{m}^{2}, 9.1 \times 10^{2} \mu \mathrm{m}^{2}$, and $1.6 \times 10^{3} \mu \mathrm{m}^{2}$, respectively. Previously, we reported that the formation rate of $\mathrm{PdLCl}$ became faster with the decrease in $\mathrm{pH}$, because the concentration of 5- $\mathrm{Br}-$ PADAP in the aqueous phase and at the interface increased due to the protonation. Therefore, smaller interfacial crystals were formed by faster nucleation under the lower $\mathrm{pH}$ condition. 


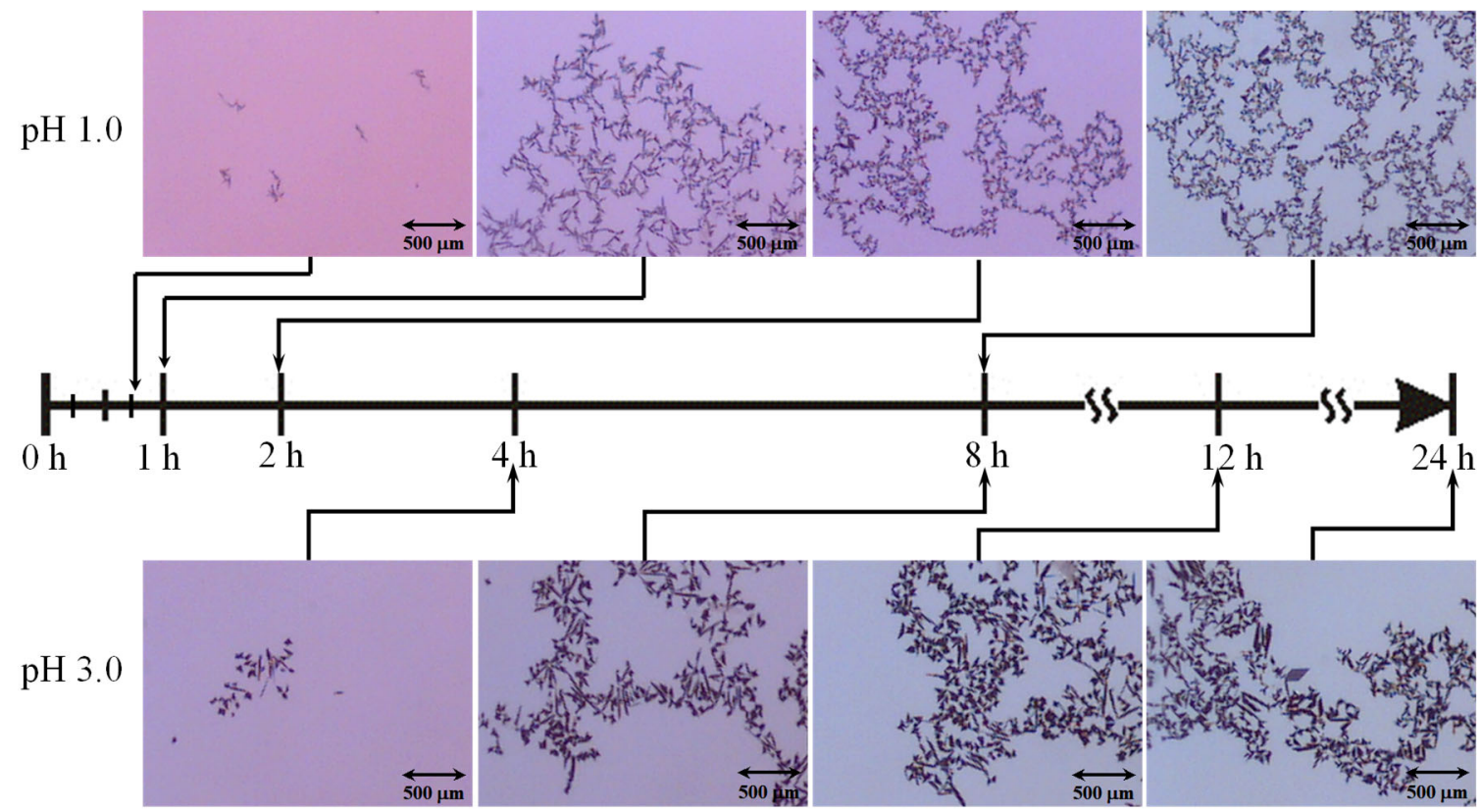

Figure 5. Dependency of PdLCl crystal growth on time at the liquid-liquid interface. $[\mathrm{Pd}(\mathrm{II})]=1.0 \times$ $10^{-3} \mathrm{M},[\mathrm{HL}]=1.0 \times 10^{-4} \mathrm{M}, 50 \%$ heptane $+50 \%$ toluene.

\section{Conclusion}

We performed a detailed study on the interfacial crystallization of $\mathrm{PdLCl}$ in the heptane-toluene mixture/water system. It was found that the crystal size distribution formed at the liquid-liquid interface depends on the solubility and the formation rate of PdLCl. The crystals formed at the liquid-liquid interface became larger under the higher toluene ratio, higher $\mathrm{Pd}(\mathrm{II})$ concentration and higher $\mathrm{pH}$ conditions. By finding optimal conditions, larger crystals could be generated at the liquid-liquid interface. Crystal formation at the liquid-liquid interface is very simple and easy since it does not require concentration of the solution and can be performed simply by bringing the aqueous phase into contact with the organic phase. The liquidliquid interface can be expected as a useful reaction field for crystal formation.

\section{Acknowledgement}

This work was supported by JSPS KAKENHI Grant Number 17K05893.

\section{References}

1) A. G. Volkov, D. W. Deamer, "Liquid-Liquid Interfaces. Theory and Methods", CRC Press, Boca Raton, FL (1996).

2) A. G. Volkov, "Liquid Interfaces in Chemical, Biological, and Pharmaceutical Applications", Marcel Dekker, New York (2001).

3) S. Tsukahara, Anal. Chim. Acta, 556, 112-120 (2006).

4) K. Kubota, S. Tanida, Y. Shirakawa, A. Shimosaka, J. Hidaka, J. Chem. Eng. Jpn., 26, 9556-9564 (2010).

5) S. Lee, P. Sanstead, J.M. Wiener, R. Bebawee, A.G. Hilario, Langmuir, 26, $9556-9564$ (2010). 
6) W. Wang, C. Y. Li, ACS Macro Lett., 3, 175-179 (2014).

7) A. Ohashi, H. Watarai, Anal. Sci., 17, 1313-1319 (2001).

8) A. Ohashi, H. Watarai, Langmuir, 18, 10292-10297 (2002).

9) S. I. Busev, V. A. Vin'kova, Zh. Anal. Khim., 22, 552-556 (1967).

10) D. A. Johnson, T. M. Florence, Talanta, 22, 253-265 (1975).

11) A. Ohashi, S. Tsukahara, H. Watarai, Anal. Chim. Acta, 364, 53-62 (1998).

12) A. Ohashi, T. Tsukuda, H. Watarai, Anal. Sci., 19, 1085-1086 (2003).

13) A. Mersmann, KONA, 16, 60-67 (1998). 